Published as: Chem Biol Interact. 2008 September 25; 175(1-3): 196-199.

\title{
ACETYLCHOLINESTERASE: MECHANISMS OF COVALENT INHIBITION OF H447I MUTANT DETERMINED BY COMPUTATIONAL ANALYSES
}

\author{
Y. H. Cheng ${ }^{1}$, X. L. Cheng ${ }^{1}$, Z. Radić ${ }^{2}$, and J. A. McCammon ${ }^{1,2}$ \\ 1 Howard Hughes Medical Institute, Department of Chemistry and Biochemistry, University of California at \\ San Diego, La Jolla, CA92093-0365 \\ 2Department of Pharmacology, University of California at San Diego, La Jolla, CA92093-0365
}

\section{Abstract}

The reaction mechanisms of two inhibitor $\mathrm{TFK}^{+}$and $\mathrm{TFK}^{0}$ binding to $\mathrm{H} 447 \mathrm{I}$ mutant mouse acetylcholinesterase ( $\mathrm{mAChE}$ ) have been investigated by using a combined ab initio quantum mechanical/molecular mechanical (QM/MM) approach and classical molecular dynamics (MD) simulations. $\mathrm{TFK}^{+}$binding to the H447I mutant may proceed with a different reaction mechanism from the wild type. A water molecule takes over the role of His447 and participates in the bond breaking and forming as a "charge relayer". Unlike in the wild-type mAChE case, Glu334, a conserved residue from the catalytic triad, acts as a catalytic base in the reaction. The calculated energy barrier for this reaction is about $8 \mathrm{kcal} / \mathrm{mol}$. These predictions await experimental verification. In the case of the neutral ligand $\mathrm{TFK}^{0}$, however, multiple MD simulations on the $\mathrm{TFK}^{0} / \mathrm{H} 447 \mathrm{I}$ complex reveal that none of the water molecules can be retained in the active site as a "catalytic" water. Taken together our computational studies confirm that $\mathrm{TFK}^{0}$ is almost inactive in the H447I mutant, and also provide detailed mechanistic insights into the experimental observations.

\section{Keywords}

ab initio QM/MM; molecular dynamics; free energy calculations; charge relayer

\section{Introduction}

Acetylcholinesterase (AChE, EC 3.1.1.7) is a hydrolytic enzyme that belongs to the serine hydrolase family. It plays important roles during the course of signal transmission at cholinergic synapses. The principal biological role of acetylcholinesterase is the termination of impulse transmissions by rapidly hydrolyzing the neurotransmitter, acetylcholine (ACh) [1-3]. Dysfunctions of AChE or other components of cholinergic synapses are involved in several human diseases, including myasthenia gravis, glaucoma, Alzheimer's and Parkinson's Diseases [4-9]. As a result, AChE has become an important target for rational drug design.

The crystal structure of AChE is characterized by a deep narrow gorge which penetrates halfway into the enzyme and contains the catalytic site located near the bottom, $c a$. $20 \AA$ deep

Publisher's Disclaimer: This is a PDF file of an unedited manuscript that has been accepted for publication. As a service to our customers we are providing this early version of the manuscript. The manuscript will undergo copyediting, typesetting, and review of the resulting proof before it is published in its final citable form. Please note that during the production process errors may be discovered which could affect the content, and all legal disclaimers that apply to the journal pertain. 
[10]. Kinetic studies have revealed that AChE possesses a remarkably high activity, with an ACh turnover rate of about $10^{4} \mathrm{~s}^{-1}$ under physiological conditions, approaching the diffusioncontrolled limit [11-13].

Similar to many other proteases, the catalytic triad in AChE consisting of Ser203(200) [14], His447(440) and Glu334(327) is believed to be essential to hydrolysis.

However, recent experimental mutagenesis studies have brought new challenges to all the above proposed reaction mechanisms. $\mathrm{TFK}^{+}(\mathrm{m}-(\mathrm{N}, \mathrm{N}, \mathrm{N}$-trimethylammonio) trifluoroacetophenone (TMTFA)) (see Fig. 1 (b)), a common inhibitor to AChE, can still react with the mouse $\mathrm{AChE}$ (mAChE), even with the replacement of His 447 by a hydrophobic Ile. In contrast, its neutral analog, $\mathrm{TFK}^{0}$, shows no apparent binding activity to H447I mutant, while it shows slightly reduced binding to the wild-type $\mathrm{mAChE}$ as compared to $\mathrm{TFK}^{+}$(Table 1).

In order to explore the enzymatic activity of H447I mutant $\mathrm{mAChE}$, we have performed computational studies on both $\mathrm{TFK}^{+}$and $\mathrm{TFK}^{0}$ binding to the wild-type and H447I mutant mAChEs, using a combined ab initio quantum mechanical and molecular mechanical (QM/ $\mathrm{MM}$ ) approach, as well as multiple MD simulations. In our study, a water molecule is found to play an essential catalytic role in place of His 447 in the binding reaction of $\mathrm{TFK}^{+}$to the H447I mutant. Along with this water molecule, Ser203 and Glu334 form a new stable catalytic triad. During the reaction, Ser203 delivers a proton to the water molecule while the water molecule serves as a charge relayer to pass one proton to Glu334. The QM/MM free energy barrier for the reaction is lower than $8.0 \mathrm{kcal} / \mathrm{mol}$. On the other hand, the water triad was unable to be retained in the corresponding $\mathrm{TFK}^{0} / \mathrm{H} 447 \mathrm{I}$ complexes from multiple MD simulations, indicating that $\mathrm{TFK}^{0}$ might not be able to stably bind to the H447I mutant. To further validate our QM/MM calculations, we also used thermodynamic integration (TI) calculations to investigate the binding energy differences between $\mathrm{TFK}^{0}$ and $\mathrm{TFK}^{+}$in both the wild-type and $\mathrm{H} 447$ mutant enzymes. The TI calculations also suggest that the binding of $\mathrm{TFK}^{+}$to both enzymes is much stronger than the neutral analog TFK ${ }^{0}$, which is consistent with experimental observations as well as the above QM/MM calculations.

\section{Computational methods}

Since there is no crystal structure of the H447I mutant so far, we tried two approaches to prepare the initial noncovalent complex structure of $\mathrm{H} 447 \mathrm{I}$ and $\mathrm{TFK}^{+}$(denoted as the $\left[\mathrm{M} \bullet \mathrm{T}^{+}\right.$] model [21]). The first approach is to use the multiple docking approach introduced by Kua et al [15]. His 447 in the apo mAChE crystal structure (PDB code: $1 \mathrm{~J} 06$ ) was manually modified to Ile, and then $\mathrm{TFK}^{+}$was docked into 1,000 snapshots evenly chosen from the last $1 \mathrm{~ns}$ trajectory of a $10 \mathrm{~ns}$ apo H447I mutant MD simulation. The Autodock 3.0 program [16] was used for all the docking studies. The search method used was the Lamarckian genetic algorithm (LGA) set at level 2 with the top 6 structures reported. Finally, according to the criteria suggested in Kua et al [15], the best 6 complex structures were selected and immersed into explicit water boxes, and subsequent MD simulations were set up to relax each system. To prevent $\mathrm{TFK}^{+}$dislocation from the esteratic binding site, a $20.0 \mathrm{kcal} /\left(\mathrm{mol} \cdot \AA^{2}\right)$ harmonic restraint between the carbonyl$\mathrm{C}$ of $\mathrm{TFK}^{+}$and Ser203- $O_{\gamma}$ was applied during simulations. The second approach is to start from the noncovalent $\left[\mathrm{W} \cdot \mathrm{T}^{+}\right]$structure obtained from our $\mathrm{QM} / \mathrm{MM}$ calculations of the wildtype enzyme with $\mathrm{TFK}^{+}$(see below for details), and then manually replace HID447 (Note: The $N_{\varepsilon}$ proton originally in the $\left[\mathrm{W}-\mathrm{T}^{+}\right]$complex is transferred to Ser203 in the $\left[\mathrm{W} \cdot \mathrm{T}^{+}\right]$model after the $\mathrm{QM} / \mathrm{MM}$ run) with Ile. Another MD simulation of the resulting system was then set up by following the same procedure as outlined in the first approach. The total number of atoms in these 7 MD simulations is around 70,000-75,000. Similarly, 7 initial models of H447I and $\mathrm{TFK}^{0}\left(\left[\mathrm{M} \bullet \mathrm{T}^{0}\right]\right)$ were obtained with the same procedure. Additionally, an 8 th $\left[\mathrm{M} \bullet \mathrm{T}^{0}\right]$ model 
was obtained by directly modifying $\mathrm{TFK}^{+}$to $\mathrm{TFK}^{0}$ in one of the $\left[\mathrm{M} \cdot \mathrm{T}^{+}\right]$models. Therefore, a total of $8\left[\mathrm{M} \bullet \mathrm{T}^{0}\right]$ models were prepared and subjected to further theoretical investigations.

\section{Results and Discussions}

As mentioned in Methods section, 7 non-covalent complex $\left[\mathrm{M} \bullet \mathrm{T}^{+}\right]$models of the H447I mutant and $\mathrm{TFK}^{+}$were obtained via docking and QM/MM calculations. During the subsequent MD simulations of these models, in 6 of 7 models, a water molecule was observed to diffuse into the center of the triangle formed by Ser203, Ser229 and Glu334 in the first $2 n s$ simulations; a representative snapshot from the simulation is shown in Fig. 2. Then we extended our MD simulations to $10 \mathrm{~ns}$ for each model. The average distance of the hydroxyl oxygen $O_{\gamma}$ of Ser203 to the oxygen $\mathrm{O}_{\mathrm{W}}$ of the water is $2.72 \pm 0.12 \AA$, the carboxyl oxygen of the Ser229 backbone to $\mathrm{O}_{\mathrm{W}}$ of the water is $2.78 \pm 0.18 \AA$, and $\mathrm{O}_{\mathrm{W}}$ of the water to one of carboxyl oxygens $O_{\delta 1}$ of Glu334 is $2.66 \pm 0.12 \AA$ in all of the $10 \mathrm{~ns}$ trajectories. Generally, an effective hydrogen bond can be characterized by the short distance between the heteroatoms (less than $3.50 \AA$ ), and the bond angle greater than $135^{\circ}[17-18]$. Using this criterion, the hydrogen bond between the Ser203 $O_{\gamma}$ and $\mathrm{O}_{\mathrm{W}}$ is found in all the structures in the $10 \mathrm{~ns}$ simulations, while the hydrogen bond between $\mathrm{O}_{\mathrm{W}}$ and $O_{\delta 1}$ is $\sim 99 \%$, and between $\mathrm{O}_{\mathrm{W}}$ and Ser229-O is $\sim 95 \%$. The water molecule is observed to flip between Ser229-O and $\mathrm{O}_{\delta 1}$, while the hydrogen bond between $O_{\gamma}$ and $\mathrm{O}_{\mathrm{W}}$ stays stable.

Three snapshots from the above MD simulations were selected to explore the acylation reaction mechanism in the H447I mutant. The water molecules beyond a $27 \AA$ A solvent water sphere, centered on the active site (the hydroxyl oxygen $O_{\gamma}$ of Ser203) were removed. The three prepared QM/MM models have 10059 atoms (562 water molecules), 10176 atoms (602 water molecules) and 10170 atoms (600 water molecules) respectively. Each snapshot was first relaxed by the MM method, and then optimized with B3LYP(6-31G*) QM/MM calculations using an iterative minimization approach [19], leading to an optimized structure for the reactant. The QM subsystem consists of the sidechains of Ser203 and Glu334, the water bridge and $\mathrm{TFK}^{+}$, with the broken $C_{\beta}-C_{\alpha}$ bonds of Ser203 and Glu334 treated as two pseudobonds [20], resulting in a total of $48 \mathrm{QM}$ atoms. All other atoms are treated by MM. The reaction coordinate (RC) is show in Fig. 3. Both forward and backward RC driving calculations yield consistent curves and all the reaction paths are smooth and continuous.

All the three $\mathrm{QM} / \mathrm{MM}$ calculations led to very consistent results, in which the water molecule between Ser203 and Glu334 plays a "charge-relay" role during TFK ${ }^{+}$binding reaction with the H447I mutant. Table 2 presents the relative potential energies in the reactant (non-covalent complex), transition state and product (covalent complex), respectively. The calculated potential energy barriers at the MP2(6-31+G*)/MM level are 8.2, 4.2, $10.6 \mathrm{kcal} / \mathrm{mol}$.

However, the "lock" can be broken easily or even never formed if $\mathrm{TFK}^{+}$is replaced by $\mathrm{TFK}^{0}$. As compared to $\mathrm{TFK}^{+}$, larger RMSDs for $\mathrm{TFK}^{0}$ have been captured in MD simulations [24].

In conclusion, we explored the $\mathrm{TFK}^{+}$and $\mathrm{TFK}^{0}$ inhibition mechanisms in the H447I mutant mAChE. Despite the replacement of the catalytic base His447, $\mathrm{TFK}^{+}$still demonstrates high binding affinity to the H447I mutant. Our computational studies suggest that a water molecule might act as a "charge relayer" and facilitate the binding of the ligand to the enzyme while this is not true for the binding of the neutral analogue $\mathrm{TFK}^{0}$. We hope that these results will stimulate further experimental studies. 


\section{Acknowledgements}

Y.H.C. thanks Prof. Palmer Taylor for helpful discussions and experimental data, and Prof. Yingkai Zhang for advice and access of his QM/MM code and his brilliant idea in simulating enzymatic reactions. This work has been supported in part by grants from the NSF and NIH. Additional support has been provided by NBCR, CTBP, HHMI, the W. M. Keck Foundation, and Accelrys, Inc.

\section{References}

1. Rosenberry TL. Acetylcholinesterase. Adv. Enzymol. Relat. Areas Mol. Biol 1975;43:103-218. [PubMed: 891]

2. Schumacher M, Camp S, Maulet Y, Newton M, Macpheequigley K, Taylor SS, Friedmann T, Taylor P. Primary structure of acetylcholinesterase - implications for regulation and function. Fed. Proc 1986;45:2976-2981. [PubMed: 3536598]

3. Taylor, P. The Pharmacological Basis of Therapeutics. New York: MacMillan; 1985.

4. Contestabile A, Fila T, Bartesaghi R, Contestabile A, Ciani E. Choline acetyltransferase activity at different ages in brain of ts65dn mice, an animal model for down's syndrome and related neurodegenerative diseases. J. Neurochem 2006;97:515-526. [PubMed: 16539660]

5. Piazzi L, Rampa A, Bisi A, Gobbi S, Belluti F, Cavalli A, Bartolini M, Andrisano V, Valenti P, Recanatini M. 3-(4-\{[benzyl(methyl)amino]methyl\}-phenyl)-6,7-dimethoxy-2h-2-chromenone (ap2238) inhibits both acetylcholinesterase and acetylcholinesterase-induced beta-amyloid aggregation: a dual function lead for alzheimer's disease therapy. J. Med. Chem 2003;46:2279-2282. [PubMed: 12773032]

6. Bachurin SO. Medicinal chemistry approaches for the treatment and prevention of alzheimer disease. Med. Res. Rev 2003;23:48-88. [PubMed: 12424753]

7. Sramek JJ, Zarotsky V, Cutler NR. Review of drug development and therapeutic role of cholinesterase inhibitors in alzheimer's disease. Drug Dev. Res 2002;56:347-353.

8. Kryger G, Silman I, Sussman JL. Structure of acetylcholinesterase complexed with e2020 (aricept (r)): implications for the design of new anti-alzheimer drugs. Struct. Fold. Des 1999;7:297-307.

9. Egan TM, North RA. Acetylcholine hyperpolarizes central neurons by acting on an $\mathrm{m} 2$ muscarinic receptor. Nature 1986;319:405-407. [PubMed: 2418362]

10. Sussman JL, Harel M, Frolow F, Oefner C, Goldman A, Toker L, Silman I. Atomic-structure of acetylcholinesterase from torpedo-californica - a prototypic acetylcholine-binding protein. Science 1991;253:872-879. [PubMed: 1678899]

11. Bazelyansky M, Robey E, Kirsch JF. Fractional diffusion-limited component of reactions catalyzed by acetylcholinesterase. Biochemistry 1986;25:125-130. [PubMed: 3954986]

12. Hasinoff BB. Kinetics of acetylthiocholine binding to electric-eel acetylcholinesterase in glycerol water solvents of increased viscosity - evidence for a diffusion-controlled reaction. Biochim. Biophys. Acta 1982;704:52-58. [PubMed: 7093289]

13. Nolte HJ, Rosenberry TL, Neumann E. Effective charge on acetylcholinesterase active-sites determined from the ionic-strength dependence of association rate constants with cationic ligands. Biochemistry 1980;19:3705-3711. [PubMed: 7407068]

14. Amino acids and numbers refer to mouse or Human AChE, and the numbers in parentheses refer to the positions of analogous residues in TcAChE

15. Kua J, Zhang YK, McCammon JA. Studying enzyme binding specificity in acetylcholinesterase using a combined molecular dynamics and multiple docking approach. J. Am. Chem. Soc 2002;124:82608267. [PubMed: 12105904]

16. Morris GM, Goodsell DS, Halliday RS, Huey R, Hart WE, Belew RK, Olson AJ. Automated docking using a lamarckian genetic algorithm and an empirical binding free energy function 1998;19:16391662.

17. Eriksson MAL, Nilsson L. Structural and dynamic differences of the estrogen receptor dna binding domain, binding as a dimer and as a monomer to DNA: molecular dynamics simulation studies. Eur. Biophys. J. Biophys. Lett 1999;28:102-111.

18. Sheu SY, Yang DY, Selzle HL, Schlag EW. Energetics of hydrogen bonds in peptides. Proc. Natl. Acad. Sci. U. S. A 2003;100:12683-12687. [PubMed: 14559970] 
19. Zhang YK, Liu HY, Yang WT. Free energy calculation on enzyme reactions with an efficient iterative procedure to determine minimum energy paths on a combined ab initio QM/MM potential energy surface. J. Chem. Phys 2000;112:3483-3492.

20. Zhang YK, Lee TS, Yang WT. A pseudobond approach to combining quantum mechanical and molecular mechanical methods. J. Chem. Phys 1999;110:46-54.

21. "M", " $\mathrm{T}^{+}$" and " $\mathrm{T}$ ", represent $\mathrm{H} 447 \mathrm{I}$ mutant $\mathrm{mAChE}, \mathrm{TFK}^{+}$and $\mathrm{TFK}^{0}$ respectively; [X-Y] and [X$\mathrm{Y}$ ] represent the covalent and noncovalent complexes of the $\mathrm{X}$ enzyme and $\mathrm{Y}$ ligand, respectively.

22. Radić Z, Quinn DM, McCammon JA, Taylor P. J. Biol. Chem 1997;272:23265-23277. [PubMed: 9287336]

23. Radić Z, Taylor P. J. Biol. Chem 2001;276:4622-4633. [PubMed: 11036076]

24. Cheng YH, Cheng XL, Radić Z, McCammon JA. J. Am. Chem. Soc 2007;129:6562-6570. [PubMed: 17461584] 
(a) Acylation

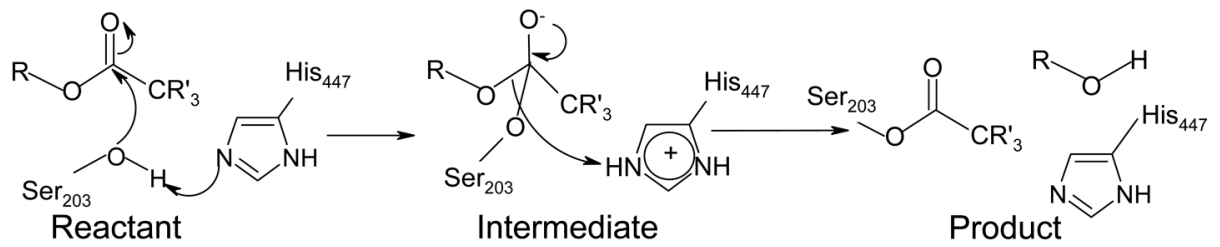

(b)

$$
R^{\prime}=H, R=(C H 2)_{2}-Y, Y=H, M e, E t, i P r, t B u
$$
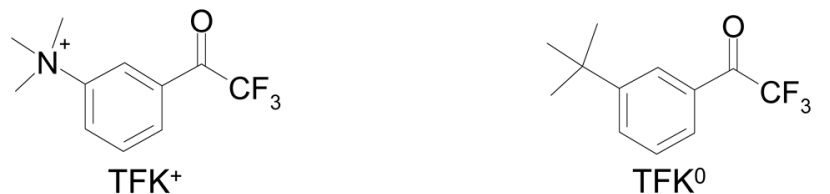

Figure 1.

(a) The acylation mechanism in the wild-type AChE enzyme; (b) The chemical structures of $\mathrm{TFK}^{+}$and $\mathrm{TFK}^{0}$. 


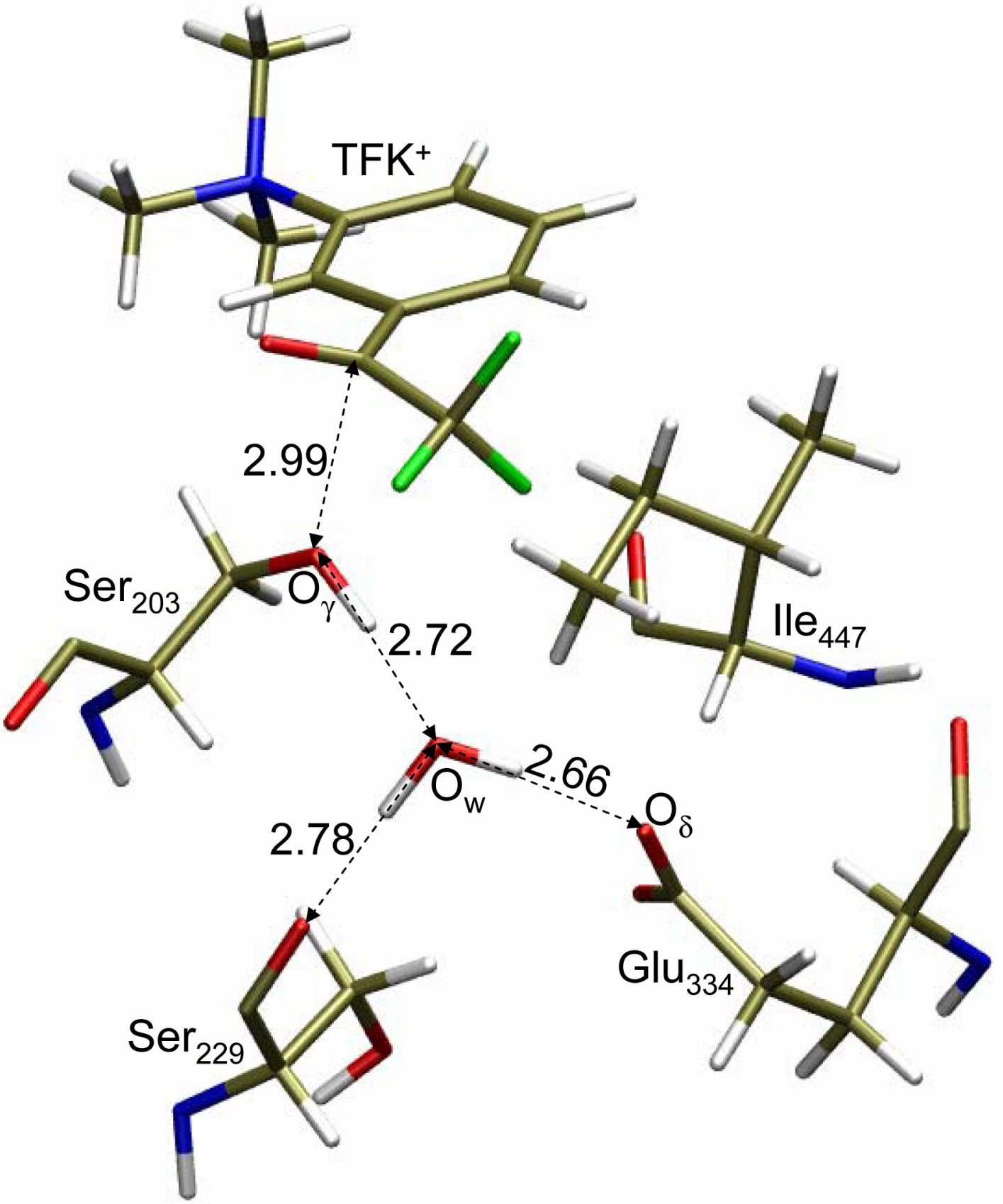

Figure 2.

The "water" triad in the active site of the six $\left[\mathrm{M} \cdot \mathrm{T}^{+}\right]$models. The values of the distances in $\AA$ are averaged among six models. 


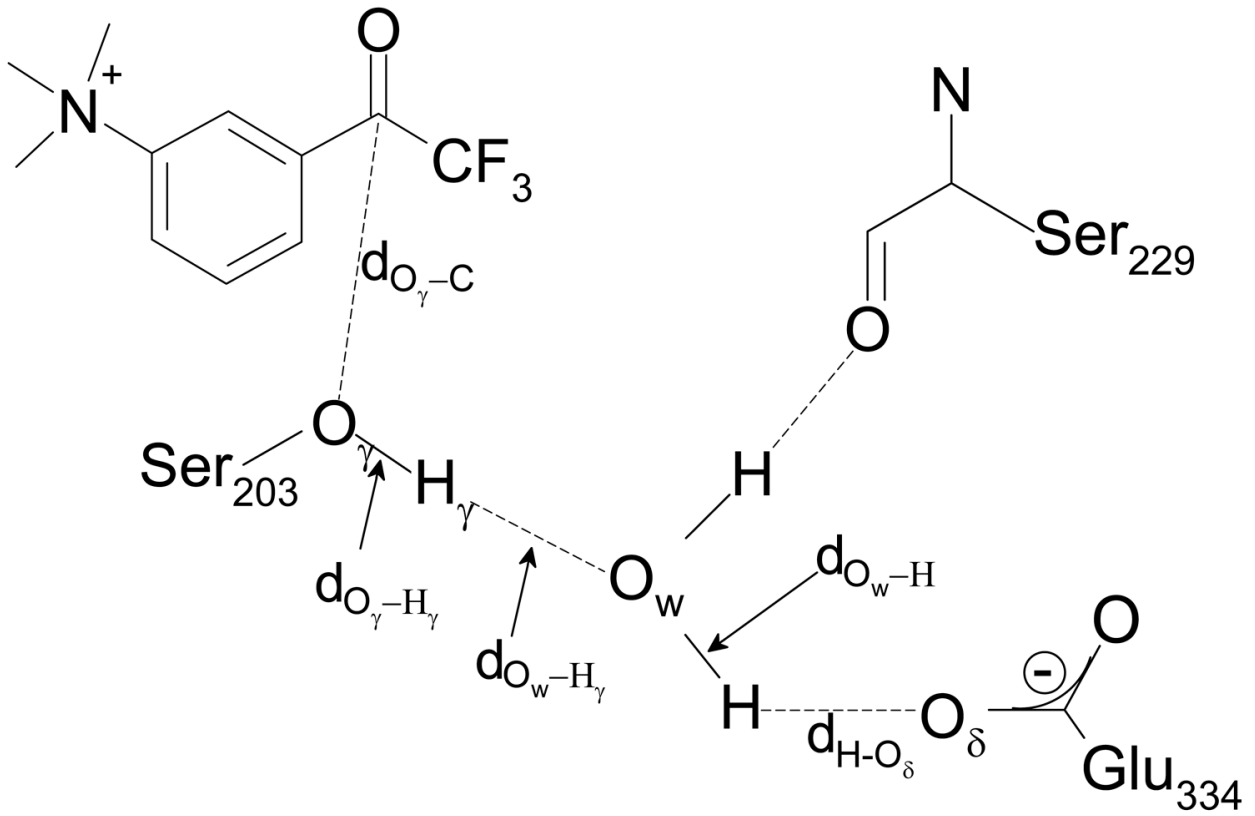

Figure 3.

Illustration of the reaction coordinate used for the $\mathrm{H} 447 \mathrm{I}$ mutant and $\mathrm{TFK}^{+}$reaction, which is $d O_{\gamma}-H_{\gamma}+d O_{w}-H-d O_{\gamma}-C-d O_{w}-H_{\gamma}-d_{H}-O_{\delta}$. 
Table 1

The rate constants for association and dissociation of inhibitors $T F K^{+}$and $T F K^{0}$ with mouse AChEs measured by experiments [22-23]. The units of $k_{\text {on }}$ and $k_{\text {off }}$ are $10^{9} \mathrm{M}^{-1} \mathrm{~min}^{-1}$ and $10^{-3} \mathrm{~min}^{-1}$, respectively.

\begin{tabular}{|c|c|c|c|c|}
\hline & \multicolumn{2}{|c|}{ wild-type mAChE } & \multicolumn{2}{|c|}{ H447I mutant mAChE } \\
\hline & $k_{\text {on }}$ & $k_{o f f}$ & $k_{\text {on }}$ & $k_{o f f}$ \\
\hline $\begin{array}{l}T F K^{+} \\
T F K^{0}\end{array}$ & $\begin{array}{l}980 \pm 60 \\
2.2 \pm 0.3\end{array}$ & $\begin{array}{c}1.1 \pm 0.3 \\
15 \pm 1\end{array}$ & $\begin{array}{l}\sim 10^{a} \\
N / A^{b}\end{array}$ & $\begin{array}{l}\sim 1.0^{a} \\
N / A^{b}\end{array}$ \\
\hline
\end{tabular}


Table 2

The calculated QM/MM potential energy differences (kcal/mol) for three QM/MM models. The geometries are relaxed at the B3LYP(6-31G*)/MM level, and then single-point calculations are performed at three different levels.

\begin{tabular}{|c|c|c|c|}
\hline & MP2(6-31+G*)/MM & B3LYP(6-31+G*)/MM & B3LYP(6-31G*)/MM \\
\hline \multicolumn{4}{|c|}{ The first snapshot } \\
\hline Reactant & 0.0 & 0.0 & 0.0 \\
\hline Transition State & 8.2 & 7.4 & 8.2 \\
\hline Product & -5.0 & -1.1 & 2.0 \\
\hline \multicolumn{4}{|c|}{ The second snapshot } \\
\hline Reactant & 0.0 & 0.0 & 0.0 \\
\hline Transition State & 4.2 & 5.8 & 7.5 \\
\hline Product & -8.0 & -2.5 & 0.0 \\
\hline \multicolumn{4}{|c|}{ The third snapshot } \\
\hline Reactant & 0.0 & 0.0 & 0.0 \\
\hline Transition State & 10.6 & 10.3 & 10.4 \\
\hline Product & 0.4 & 3.8 & 4.4 \\
\hline
\end{tabular}

